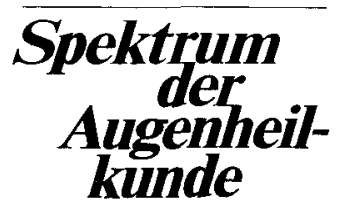

(C) Springer-Verlag 2000 Printed in Austria

\title{
Kongressberichte
}

\section{0th Congress of the European Contact Lens Society of Ophthalmologists}

\section{P. Drobec}

Die 30. Tagung der ECLSO, der europäischen Vereinigung der kontaktlinsenanpassenden Augenärzte fand diesmal vom 27. bis 30 . September 2000 in der Südtürkei, in Antalya statt. Die lokalen Organisatoren hatten sich sehr bemüht, um einen klaglos funktionierenden Kongress auf die Beine zu stellen. Die Tagung war in dem luxuriösen Sheraton Voyager Hotel direkt am Ufer des türkisfarbenen Meeres lokalisiert. Prächtig sonniges Spätsommerwetter machte es einem

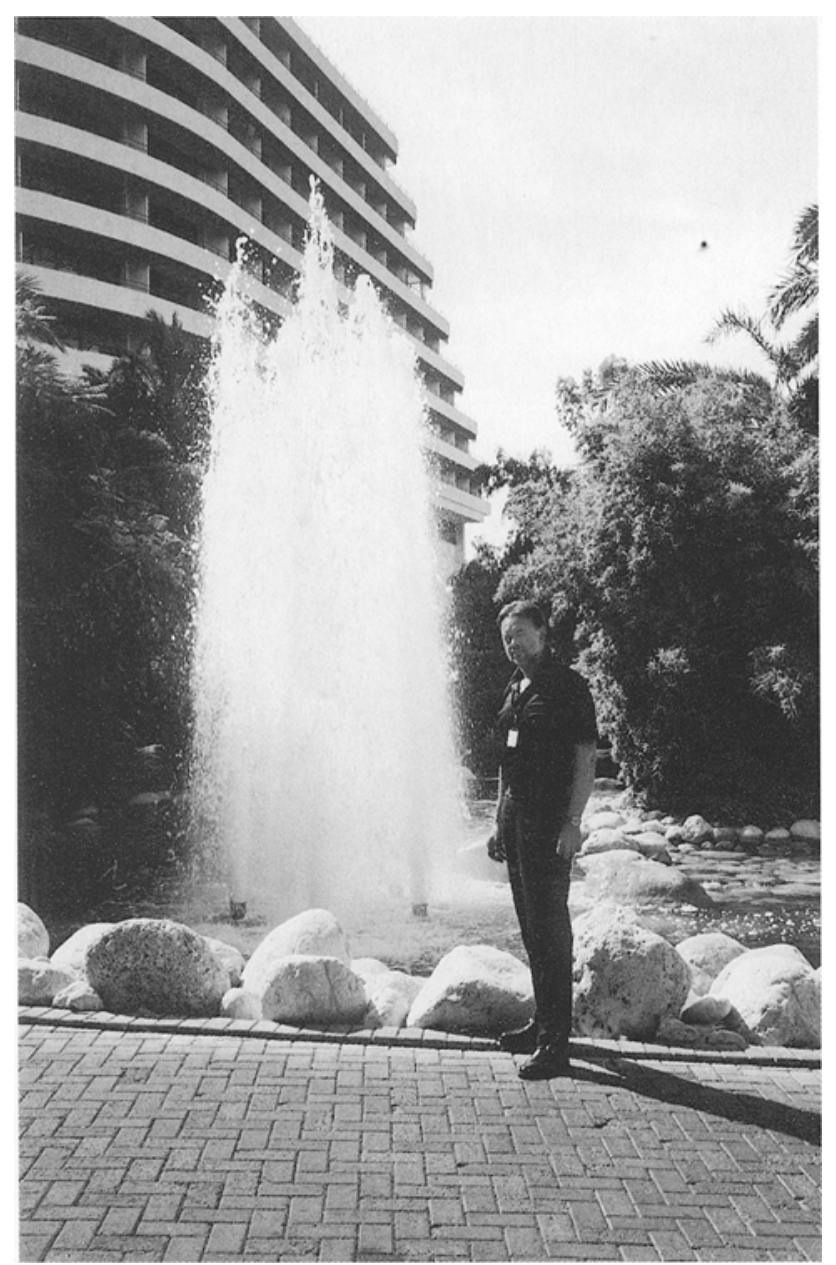

Abb. 1. Das Sheraton Hotel in Antalya, Tagungsort des 30. Kongresses der ECLSO oft sehr schwer, in den verdunkelten Vortragssälen auszuharren. Das Rahmenprogramm führte die Tagungsteilnehmer in die antiken Städte Side, Perge und Aspendos. In dem großen Amphitheater von Aspendos wohnten wir einer Aufführung der Oper La Traviata von Giuseppe Verdi bei. Am letzten Abend wurden wir zum Galadiner in den Park des Sheraton-Hotels geladen und dinierten bei festlichen Darbietungen unter riesigen Königspalmen.

85 Vorträge spannten einen weiten Bogen über die Spezialgebiete der Kontaktlinsen. Folgende Themen wurden vorgetragen und diskutiert: Die Topographie der Hornhaut, die Videokeratographie, der Keratokonus, die refraktive Chirurgie, Komplikationen der refraktiven Chirurgie und Kontaktlinsenversorgung danach, das trockene Auge, die therapeutische Linse bei Hornhauterosionen, Infektionen, Pflegesysteme, multifocale Kontaktlinsen (weich und formstabil), Tageslinsen versus Linsen mit verlängerter Tragedauer, die Astigmatismuskorrektur. Ausführliche Zusammenfassungen aller Vorträge sind in den CONTACTOLOGIA (F. Enke-Verlag, Stuttgart) Band 22, Heft 3/4, Seite 119-141 abgedruckt.

Bei der Delegiertenversammlung und bei der Generalversammlung wurden die zahlreichen Probleme der kontaktlinsenanpassenden Augenärzte und der ECLSO vorgetragen und diskutiert. Die Problematiken unterscheiden sich in den einzelnen europäischen Ländern nur wenig. In einem Fragebogen wurden die Praktiken der Kontaktlinsenverordnung bzw. Kontaktlinsenabgabe durch die Ophthalmologen, die Optiker, die Warenhäuser und sogar via Internet erhoben und evaluiert. Dabei kam wieder einmal zutage, dass die Situation in Österreich für uns Augenärzte als sehr günstig zu bezeichnen ist. Andere Länder können von unseren Regelungen nur träumen.

Neuwahlen in den Vorstand der ECLSO stellen wie in allen Oranisationen auch ein Problem dar. Insbesondere die Nachbesetzung des jahrelangen Generalsekretärs R. Fritsch ist schwierig, da die Kontinuität der Arbeit und der Präsentation nach außen gewahrt werden muss.

Sehr breiter Raum wurde auch der Dikussion um die Zeitschrift der ECLSO gegeben. Die CONTACTOLOGIA können in dieser Form fast nicht mehr finanziert werden. Man war sich einig, dass ein Publikationsorgan weiterhin bestehen bleiben muss. Für nächstes Jahr werden nun Modelle der günstigeren Finanzierung und der weiteren Verbreitung der Abonnements erarbeitet

Die nächsten Kongresse der ECLSO sind im Mai 2001 in Santander (Spanien), im Jahr 2002 in Bordeaux (Frankreich), im Jahr 2003 in Venedig (Italien), im Jahr 2004 in Budapest (Ungarn) und im Jahr 2005 in Jerusalem (Israel) geplant. Für das Jahr 2006 kandidiert Österreich mit der Kongressstadt Wien. 